\title{
Commodification of transformation discourses and post- apartheid institutional identities at three South African universities
}

\author{
Felix Banda and Lynn Mafofo
}

\begin{abstract}
Using mission statements from the UCT, UWC and Stellenbosch University (South Africa), we explore how the three universities have rematerialised prior discourses to rebrand their identities as dictated by contemporary national and global aspirations. We reveal how the universities have recontextualised the experiences and discourses of liberation struggle and the new government's post-apartheid social transformation discourses to construct distinctive identities that are locally relevant and globally aspiring. This has led to the semiotic refiguring of universities from spatial edifices of racially based unequal education, to equal opportunity institutions of higher learning, and to the blurring of historical boundaries between these universities. We conclude that the universities have reconstructed distinct and recognisable identities which speak to a segregated past, but with a post-apartheid voice of equity and redress.
\end{abstract}

\section{Introduction}

Focusing on mission statements, the paper explores how the University of the Western Cape (UWC), a historically black university (HBU), and two historically white universities (HWUs) the University of Cape Town (UCT) and Stellenbosch University (SU) have appropriated and blended aspects of the discourses of the liberation struggle and government's social transformation to market themselves as unique institutions with differentiated brand identities. Struggle discourses include the universities' (in)direct references to their role against the apartheid regime, while transformation discourses includes extrapolations from governed policy documents, especially the White Paper on Transformation of Higher Education of 1997 and the Higher Education Acts of 1997. The focus is on the commodification and repurposing of struggle and transformation discourses to advertise the universities to potential clients. Fairclough (1993) defines commodification of discourse as a more general application of instrumental or 'means-end' rationality to discourse. Commoditised discourses tend to be formulaic in their proclamations of change and hence tend to ignore differences in contexts as their effect is to normalise, homogenise, and reduce differences. We use the notion of semiotic remediation (hence forth remediation) (Prior \& Hengst, 2010) to illustrate the repurposing of struggle and transformation discourses, in the universities' mission statements, as promotional discourse; which, it is argued, has led to the blurring of boundaries between previously advantaged and previously disadvantaged universities. 


\section{Socio-historical contexts}

Historically, South African universities were part of the apartheid material world as they formed part of the segregated spatial semiotics. Universities were designed to play their part in the grand apartheid scheme of separate education among racial groups. This means there were White, African, Coloured, and Indian universities. Since White was supreme, the white designated universities had a higher budget than 'black universities' as the non-white universities were collectively called. HBUs had to be content with gross limitations in resources, educational opportunities, and access to research support (Moodie, 1994). Moreover, HBUs and HWUs differed significantly in terms of student demographics and curriculum offerings. Whereas HWUs had a curriculum comparable to the best in the world, HBUs were instituted to produce the administrative corps for the Bantustans and partly to serve the regime in low-level administration positions. UWC was one of the bush universities' instituted in 1959 for 'Coloureds' (mixed race population) to offer clerical and manual labour to whites (Cooper \& Subotsky, 2001).

However, HBUs did not accept these inequalities; they mobilised their students and staff to fight against the unjust measures which privileged white students and staff in white universities (Cooper \& Subotsky, 2001). For example, Lalu (2012) notes how at the height of apartheid in the 1980s UWC published a mission statement in which it rejected the main elements of the then state imposed definition of its role as a Coloured university meant to produce low level graduates who would work as subordinates to whites. It embraced nonracial policy in its admission of students and despite the apartheid ideology and structures in place all around it. In the 1980s, UWC mission statement categorically defined itself a new role in which it sought to apply itself to functions that foster the political, social, and economic advancement of all, the disadvantaged groups in particular (Lalu, 2012). It also embarked on an overhaul of the curriculum to be in line with international standards (Lalu, 2012). The mission statement was not only at odds with the apartheid ideology; it had specific policy guidelines designed to completely 'change the character of the university' (Wolpe, 1995, p. 283).

The HWUs had their own complex alienations as they were built on the foundations of conflict between British and Afrikaner empires. Identification with an international academic culture was particularly important at these institutions, as was the backing from big South African businesses, which were entirely white owned. Afrikaner and British nationalisms were often points of pride for white universities. For instance, the then South African college for white people only, was founded in 1829 as a boys' college and later evolved to the now UCT in 1918 on the basis of the Alfred Beit legacy and additional generous gifts from the mining tycoons namely Julius Wenher and Otto Beit. It also received support from the Cape Town society and noteworthy state grants (Cooper \& Subotsky, 2001). In addition to catering for white students of British heritage, UCT also adopted English as its medium of instruction. It is noteworthy UCT started to enrol the first small group of black students as early as the 1920 despite the segregation laws during apartheid. However, the number of black students remained relatively low until the 1990s. The rise of students in protests by blacks against the regime's impositions and to demand high quality university education forced UCT to open its doors further, and as these protests spread countrywide, UCT started to read and welcome the signs of change in the country thereby committing itself to a deliberate and strategised process of internal transformation (Moodie, 1994). 
SU was first established as Victoria College in 1865 and was changed to its current name in 1918. It was opened as a result of the white Afrikaner elite's determination to establish their own university because of the nationalist conflict with the British (Gerhart, 1978). Therefore, the rising Afrikaner nationalism and sentimentalists helped to raise funds to enable the college to become a fully fledged university (Cooper \& Subotsky, 2001). The regime passed the University Act, which saw the Victoria College becoming an independent university, with all its privileges and duties in 1916. In contrast with UCT, SU adopted Afrikaans as its medium of instruction. Despite the linguistic and cultural conflicts between the white British and the white Afrikaners, these two universities shared privileges such superior infrastructure, qualified academics and research funding, all of which were in limited supply or non-existent at HBUs.

\section{Struggle and transformation discourses}

Struggle discourses can be said to refer to protest discourses by individuals and nongovernmental organisations against the apartheid regime. Such discourses include those surrounding the Sharpeville Massacre on 21 March 1960, in which the apartheid regime opened fire on protesters who went to a police station in the Township called Sharpeville to offer themselves for arrest for defying Pass laws; and those related and fuelled by the Soweto Uprising on 6 June 1976 in which black school children protesters were killed for their objection to the introduction of Afrikaans as a medium of instruction in black schools. In postapartheid South Africa, there is often reference to these past experiences, suffering, and general marginalisation of non-white South Africans, and the need to do something about it as a way of redressing past wrongs. We want to argue that elements of struggle discourses have come to define what can be said to be transformation discourses and narratives in the new South Africa spearheaded by private and non-governmental institutions, as well as government policy charting the paths for political, social, or economic transformation to benefit all South Africans regardless of race, gender, or disabilities. Those that directly or indirectly claim and in some cases are able to narrate claims of being jailed for their activism, or that they had been involved in the struggle against apartheid, qualify for what we shall call 'struggle credentials'. This includes those who were in the anti-apartheid movement, and generally the majority non-white South Africans.

Government policy documents, on the transformation of higher education, such as The White Paper 3 on Transformation of Higher Education of 1997 (hence forth Ministry of Higher Education [MoE], 1997a) and The Higher Education Act 101 of 1997 (hence forth MoE, 1997b) contain the vision, policy goals and objectives for higher education. The core of aim of transformation is equity and redress summarised in $\operatorname{MoE}$ (1997a, p. 11) as:

[F]air opportunities both to enter higher education programmed and to succeed in them. Applying the principle of equity implies, on the one hand, a critical identification of existing inequalities which are the product of policies, structures and practices based on racial, gender, disability and other forms of discrimination or disadvantage, and on the other a programme of transformation with a view to redress. Such transformation involves not only abolishing all existing forms of unjust differentiation, but also measures of empowerment, including financial support to bring about equal opportunity for individuals and institutions. 
Even as institutions were expected to transform and to redress past and current inequalities, they were also expected to maintain local and global competitiveness in academia and research (cf. MoE, 1997a, 1997b). It is not clear how local and global excellence would be achieved when the contradictory consequences of the legacy of inferior education and institutionalised socio-economic inequalities are still experienced by the majority of South Africans. However, our argument is that it is in these documents and discourses contained in them that the various mission statements directly or indirectly draw for their inspiration.

We are mindful the concept of transformation is defined differently by different interest groups and that the transformation debate in post-1994 South Africa has not been confined to government documents alone. As shown below, there is a steady and growing literature that has tapped into the transformation debate. A number of publications and key concepts such African Renaissance have drawn on the transformation debate to define South Africa's and Africa's role in globalisation (see Alexander, 1999; Boesak, 2006; Makgoba, 1999; Mbeki, 1998). Hibbert and Van der Walt (2014) look at transformation in higher education from the classroom language practices. They lament the fact that more than two decades of democracy and numerous documents and government policy on the issue, transformation has not taken place in the classroom as English (with few exceptions, Afrikaans) remain the language of classroom practice. Madiba (2014) suggests terminology development as a possible avenue to equip African languages to be full-fledged languages of academia, while Makalela (2014) proposes translanguaging (the use of multiple languages for classroom discourse) as a possible strategy to transform classroom practice in higher education.

Murray (2012) explores transformation of UWC through changes in its spatial and architectural design over time. Of interest is its institutional histories layered in older buildings characteristic of the apartheid era Public Works Department's stamp of the 1960s seen in the 'stucco plaster, strip steel windows, terrazzo details, and dark brown brickwork' (Murray, 2012, p. 60 ), to the newer open space designs of the 1980 s and later years. In terms of spatial and architectural design, SU and UCT are known for their Dutch and Victorian influences, respectively (Mafofo \& Banda, 2014). For years, the statues of the main benefactors of the two universities, Jan Marais for SU and John Cecil Rhodes were stark reminders of Dutch/Afrikaner and British imperialist interests in South Africa. The simmering tension on whether South Africa should retain colonial relics and symbols, which had been going on for a while, found focus in Cecil John Rhodes' statue which entered the transformation of UCT) debate, being uprooted from UCT's main entrance on 9 April 2015 and taken to unknown place for safe keeping. For more than a month before its removal, students had laid siege to the Cecile John Rhodes statue demanding for its removal.

However, even before the events that led to the removal of the Rhodes' statue came to the fore, some studies (Bangeni \& Kapp, 2005; Buhle, 2013; Kapp \& Bangeni, 2011) appeared to suggest that rather than transform itself and embrace diversity, UCT tended to assimilate non-white students into 'white' (English) culture. Kapp and Bangeni (2011, p. 199) illustrate how some coloured and black students felt 'judged' and 'stigmatised' for not acquiescing to the culture of speaking English like white people, while those that adopted white (English) accents risked being ostracised as 'coconuts' (a reference of being black outside, but white inside) when they got back to their homes/communities. Buhle (2013) in his study on transformation and interracial interactions at UCT argued that black students had to 
perform 'whiteness' through adopting white (English) cultural attributes and mannerisms to be accepted in certain UCT social circles. Although, perhaps, no malice was meant by SU foregrounding Afrikaans as language of academia (while supporting and partnering English and Xhosa language practices), this is often interpreted as SU continuing with white Afrikaner dominance through insisting on use Afrikaans, which for historical reasons many blacks still resist to speak or are unfamiliar with (Mafofo \& Banda, 2014).

\section{Mission statements in academia}

There is growing interest in universities' mission statements and particularly how they are used for branding and marketing purposes. However, almost without exception the studies have focused on universities in Asian, European, and the USA. It is with this caveat that the review of literature should be seen. Drawing from the study on British universities' mission statements, Fairclough (1993) posits that the university mission statements are now sliding along a continuum between telling and selling through both visual and verbal means. Universities seem to be succumbing to the pressures of 'globalisation' and marketisation which force them to operate as if they were 'ordinary businesses competing to sell their products to consumers' (Fairclough, 1993, p. 141). In this way, the university mission statements in academia can be seen as instantiations of the commodification of language. The traditional role of university mission statement to provide students with objective information therefore becomes subjugated to the imperative of promoting the university and accentuating its appeal to target 'consumers'. In this sense, the lines between 'telling and selling' (Fairclough, 2003, p. 257) therefore become distorted.

Teo carried a comparative analysis of two Singapore universities' prospectuses and acknowledges that the articulated messages in the statements have implications to the identities of universities that are constructed 'for public consumption as well as the [authority] relations between academics and students' (2007, p. 99). That is, mission statements serve as articulations of institutional purposes and they act as mantras of organisations to build togetherness among the management and help publicise institutional values to the potential customers outside the organisation. They also function as persuasive abstractions and discursive means to promote the institutions and their sources including potential students. Therefore, the mission statements in academia can be regarded as corporate or organisational texts used for institutional brand identification, and legitimation of dominant ideology (DeGenaro, 2009, p. 103).

Atkinson's (1997, p. 23) argues that university mission statements represent several discourse models as in most instances, 'a mission statement is required and as such institutions comply and write them'. Copying, sharing, cutting, and pasting among the universities' mission statements is common, and the exercise of producing the mission statements seems very deliberate indeed, as seen from the structural choices deployed by producers. Thus, in terms of genre, mission statements represent a type of promotional piece of writing (cf. Fairclough, 2003).

In this connection, Bee (2001) shows that the mission statements and slogans of Singapore educational institutions draw on the discourses related to the history, politics, social circumstances, and economics of the nation. Through reframing the discourses as promotional material, the universities are able to sell themselves as an investment that must have its 
payoff in the economy. It is believed that education has a twofold purpose. Firstly, that of training people and secondly, providing a link with the industry. It thus allows a workforce to be trained and for the economy of the state to strive. Therefore, a concern for survival is seen as one of the main issues in the academic institutions' mission statements.

Therefore, it can be argued that universities have realised that creating unique identities is vital for their growth and survival. For instance, university competitiveness, ranking, and international benchmarking are critical to European and Asian universities which are rebranding themselves as 'world-class' or 'global' universities (cf. Altbach \& Knight, 2007). Moreover, Fairclough (1993), Wernick (1991), Mautner (2005) and Osman (2006) have shown that modern universities have used marketing discourses that portray themselves as innovative and entrepreneurial institutions. Universities are thus propelled to function as businesses (Fairclough, 1993) not only in terms of attracting prospective students and staff but also in generating revenue for themselves through research.

Developments in multimedia and information technology have been critical in making available novel modalities in which universities can market themselves. For instance, websites and social networks, such as Facebook have become integral to marketing strategies of universities. Thus, as communication techniques continue to evolve, universities are also finding new ways to get in touch with clients. There is increasing evidence of institutions introducing marketing strategies which make much greater use of an ever growing range of technological options such as click internet advertising, social networking sites, and texting (Friedman, 2005). Media technological developments and related editing tools have enabled universities to creatively display mission statements and other promotional material at strategic positions on web pages (Osman, 2006).

In this regard, Van Riel (1997) argues that due to the massive competition among universities, every institution's identity must be clear so as to be used as the organisation's benchmark against which its products and services, performances, and accomplishments are measured. Consequently, universities strive to develop distinct and recognisable identities. The purpose for universities to venture into identity positioning is not to try and sell a product or service but to communicate an identity (Bulotaite, 2003), as identity will in turn give the university a platform in which it can compete with others. Traditionally, identity positioning involves focusing on points of differentiation that set each brand apart from its competitors (Aaker, 1996) and such points of differentiation are what customers remember about a brand. Thus, an effective identity will have a brand that captures the distinctive mission, aspirations, and strengths of an institution and appeals to the motivations and interests of the marketplace. This is particularly important in the changing time as it positions the university forward (Bulotaite, 2003). Therefore, brand positioning is according to Aaker (1996) inspirational in the sense that it shapes the identity and how it has to be consumed, which in turn provides direction, purpose and meaning of the university.

\section{Notions of interdiscursivity, intertextuality and remediation}

A number of writers have drawn attention to the increasing importance of language as social semiotics in everyday practices in the late modernity (Gee, 1990; Fairclough, 2003). Hybrid speech forms and texts and the increasing practice of blending modes and genres in the modern era have given new meaning to what it means to be literate. Gee (1990) perceives 
interdiscursivity as a matter of how a discourse type is constituted through a combination of elements of orders of discourse or the presence or trace of one or more discourses within another. Thus, interdiscursive language rearticulates the already existing discourses. It occurs when participants appropriate and reconstruct discourses associated with other participants. This process involves a generative reconstruction of a discourse rather than a recapitulation or imitation. Ingenuity in the reconstituted social identities lies in semiotically remediating texts through recontextualisation and blending of different discourses and styles in particular ways. In this idiom, interdiscursivity 'refers to more innovative attempts to create hybrid or relatively novel constructs by appropriating or exploiting established conventions or resources associated with other genres and practices' (Bhatia, 2004, p. 392). It thus accounts for a variety of discursive processes and professional practices that often result in mixing, embedding, and bending of generic norms in professional contexts. Interdiscursivity as an element of critical discourse analysis, according to Benwell and Stokoe (2006, p. 114) 'traces the effect of other texts and... registers in texts and interactions and describes the resultant hybridisation of discourse'.

Therefore, an interdiscursive analysis allows us to assess how prior texts and linguistic styles initiate causal effects of agency in the concrete event and the causal effects of practices and structures, in the (re)formulation of the universities' identities. The idea is to detect shifts in the relationship between orders of discourse and networks of social practices as these are reregistered in the interdiscursivity of texts. Similarly, Johnstone (2008, p. 166) perceives interdiscursivity as 'the ways in which discourses draw on previous discourses'. That is, text producers reuse and refer to the already existing text-types and the discursive practices in which they are embedded. There is thus a relationship between interdiscursivity and intertextuality in that blended prior texts hint at prior meanings. However, in this paper the notions of interdiscursivity and intertextuality are supplemented by the notion of remediation (Prior \& Hengst, 2010) as a way to move beyond mere reference to prior material and discourses. The idea is to explain how prior material and discourses are repurposed, that is, re-used as choices in semiotic resources for new and expanded meanings in the new contexts. Remediation is thus defined as referring to how people routinely rework discourses through re-voicing words of others in speech, reporting and re-presenting ideas, events and activities in different media, leading, in the process, to reconstruction of both their environment and themselves (Prior \& Hengst, 2010). In using remediation, we are hoping to show how universities draw on the same semiotic material to reconstruct themselves and their environments in differentiated ways. We elaborated on the notion of remediation below.

\section{The study}

Following Fairclough (2003), the study is text-based discourse analysis. The mission statements culled from the three universities websites constituted the texts analysed. The mission statements are situated activities located in the universities' material world (see Scollon \& Scollon, 2003). They are sets of interpretive material practices that make visible the world of the universities concerned. Hence, the paper followed the interpretive paradigm which sees the social world as a process that is created by individuals. Social reality, as it exists outside the consciousness of any individual, is thus regarded as a network of assumptions and inter-subjectively shared meanings (Morgan, 1983). These assumptions lead to the belief that there are shared multiple realities which are sustained and changed 
depending on the reality being discursively created at a particular time. The goal of interpretive research is thus to find out the orders of discourse that prevail within the phenomenon under consideration. This is in line with Fairclough's (2003) argument that scientific knowledge is socially constructed and socially sustained; and that its significance and meaning can be understood within its immediate social contexts. Consequently, the interpretative research enabled an examination of the universities' identities as formulated through semiotically remediated (Prior \& Hengst, 2010) historical, cultural, political, and social discourses in the mission statements. Prior and Hengst (2010, pp. 1, 6) argue that semiotic remediation 'represents a basic dialogic process that interdiscursively weaves together modes, media, genres, and events ...' '... through taking up the materials at hand, [and] putting them to present use, and thereby producing altered conditions for future action'. This dialogic approach to semiotics entails 'understanding signs of all kinds as dialogic, not generated out of abstract systems, but drawn from a history of sign use, tuned to the present interaction, and oriented to future responses and acts' (Prior \& Hengst (2010, p.7). Attention was on the semiotic affordances of the intertextual and interdiscursive chains related struggle and social transformation discourses that were reused and re-represented in the mission statements.

As the mission statement pages on the websites are hypertexts, the pages such as those of the history, values, logos, and location of the universities were also downloaded. Keeping these electronic versions in their original format was important to enable a comparison of the texts in a multimodal form. However, since the mission statements are devoid of multimodal appendages (other than the universities' different colour schemes), the present paper focuses on the linguistic rather than on the multimodal presentation of the mission statements. Interest is on interdiscursivity, intertextuality, and remediation as depicted in the words used in the mission statements. Thus, mission statements are seen as situated discourses and as products of compositional practices in the re-materialisations of prior talk and text, and 'drawing into a single historical trajectory' and chains of activities (Gilje, 2010, p. 497).

\section{Struggle and social transformation discourses in mission statements}

We argue that the mission statements show that the universities have commodified and repurposed texts from struggle and social transformation discourses to market themselves to potential students and stakeholders. Social semiotically, this functions to refigure universities from spatial edifices of racially based unequal education, to equal opportunity institutions of higher learning.

\section{Remediation liberation and social transformation discourses at UWC}

UWC's mission statement can be summarised as emphasising its African and international credentials as well as its commitment to be the catalyst to promote cultural diversity and the needs of a nation in transition to meets its African and international obligations. It also draws itself a unique role and status as the centre of opposition to the apartheid regime, and hence to be better able to understand the need for open access to higher education to historically disadvantaged groups.

\section{The UWC's mission statement}


The UWC is a national university, alert to its African and international context as it strives to be a place of quality, a place to grow. It is committed to excellence in teaching, learning and research, to nurturing the cultural diversity of South Africa, and to responding in critical and creative ways to the needs of a society in transition. Drawing on its proud experience in the liberation struggle, the university is aware of a distinctive academic role in helping build an equitable and dynamic society. In particular it aims to:

1. advance and protect the independence of the academic enterprise.

2. design curricular and research programmes appropriate to its southern African context.

3. further global perspectives among its staff and students, thereby

4. strengthening intellectual life and contributing to South Africa's reintegration in the world community.

5. assist educationally disadvantaged students gain access to higher education and succeed in their studies.

6. nurture and use the abilities of all in the university community.

7. develop effective structures and conventions of governance, which are democratic, transparent and accountable.

8. seek racial and gender equality and contribute to helping the historically marginalised participate fully in the life of the nation.

9. encourage and provide opportunities for lifelong learning through programmes and courses.

10. help conserve and explore the environmental and cultural resources of the southern African region, and to encourage a wide awareness of these resources in the community.

11. co-operate fully with other stakeholders to develop an excellent, and therefore transformed, higher education system.

UWC not only deploys struggle credentials/discourses, it also reframes parts of Section 1.14 of MoE (1997a, p. 11) as its own vision of higher education. It puts itself in the forefront of championing social transformation as well as contributing to the advancement of all forms of knowledge and scholarship [that] address the diverse problems and demands of the local, national, southern African and African contexts, and uphold rigorous standards of academic quality'. The mission statement does so through self-promotional claims that emphasise a prestigious and favourable status of the university.

The University of the Western Cape is a national university, alert to its African and international context as it strives to be a place of quality, a place to grow. It is committed to excellence in teaching, learning and nurturing and research.

Phrases such as it is a 'national university, a place of quality and a place to grow' are typical of the prestige advertising genre (cf. Fairclough, 1993, 2003). Having the above sentence in the topic position, the mission statement creates a slant aimed to attract and to predispose the reader to have a positive image of the institution. In line with the sociolinguistics of globalisation (Blommaert, 2010), the opening simultaneously links the institution with both translocal and global aspirations and mobility. The self-promotion is also seen in the incremental role and status the university prides itself through positioning itself as a 'national', 'African' and 'international' player. Thus, UWC deftly refigures aspects of MoE (1997a) and redefines itself from a bounded apartheid institution, that is, as from a 'bush university' for coloureds to 
being both African and international. This is framed for public consumption and meant to market itself to potential clients as well as benefactors (Teo, 2007). It is worth noting that as a previously disadvantaged 'black' university, one would expect UWC to use this to market itself favourably. Ironically, this would mean accepting the imagining of UWC as an instrument of apartheid's segregated higher education, which it had rejected and sought to dismantle right from its inception. On the contrary, UWC positions itself not only as an opportunity institution, but also as one of the best universities in Africa and the world. It is for this reason that the nominal verbs in the phrase 'excellence in teaching, learning, and nurturing research', are borrowed from the discourse of educational management as 'evidence' and also to emphasise the claims to the prestigious and favourable status of the university.

In the above example, we see what can be said to be remediated (Prior \& Hengst, 2010) extrapolations from government policy documents being blended with education management discourse to create what Fairclough (2003) calls marketisation discourse.

As nominalisation has potential reconstructive effects on organisational identities and social relations (Iedema, 2003), remediation of various discourses enables the reconstruction of the university's identity and its social relations in the country and the world through tapping into other social meanings and experiences, which are then repackaged as part of the new institutional identity. Thus, we see in UWC's mission statement discourses on race- based inequalities or gender biases as mentioned in both MoE (1997a) and MoE (1997b) being recontextualised as its own (UWC's) fight against inequality during the apartheid era, and further as a commitment to take the lead in transforming the new South African society through 'nurturing [its] cultural diversity ... and to [respond] in critical and creative ways to the needs of a society in transition'. In essence, UWC not only legitimatises the dominant ideological position in place (DeGenaro, 2009), it also repurposes the government's agenda of social transformation as its own marketing discourse through taking the lead in being 'critical' and 'creative' in finding solutions to problems that beset a society in transition.

On the other hand, UWC's mission statement delegitimises the apartheid ideology and social order through reference to the liberation struggle and pro-democracy claims in the following extract:

Drawing on its proud experience in the liberation struggle, the university is aware of a distinctive academic role in helping build an ... equitable and dynamic society ...

The twin adjectives in 'an equitable and dynamic society' have been refigured from political polemics and from MoE (1997a) and MoE (1997b), which keep referring to the need for a democratic, non-racial and dynamic South Africa. These twin adjectives become part of the sales-promotional elements to be consumed by prospective students and other potential clients (see also Altbach \& Knight, 2007; Osman, 2006). The commodification of political discourse elevates it into new form that has to be consumed as sales-promotion text. Thus, UWC's aim is not necessarily about scoring political points or about making a political statement, but is more about being able to compete in a market place, where the present ruling regime is the biggest player. Fairclough (1993, p. 144) notes, universities are increasingly obligated to 'operate under government pressure as if they were businesses competing to sell their products to consumers'. In this case, the aim is to use the resulting discourse as selling points to 
garner government support as well as to market themselves to attract potential students and institutional funders who are likely to support institutions that are mandated and have the support of the government of the day.

UWC does not directly mention black or coloured race as sales resource, but one way it has tried to distinguish itself from the other two universities is to overtly stress the liberation struggle credentials, that is, its involvement in the struggle and its defiance against the apartheid regime, which are subtly repurposed as promotional discourse. Consider the following:

In particular it aims to: advance and protect the independence of the academic enterprise ... further global perspective ... and contributing to South Africa's reintegration in the world community ... develop effective structures and conventions of governance, which are democratic, transparent and accountable ... [Our emphasis]

The literature suggests UWC refused to be a Coloured only university and defied the apartheid curriculum through modernisation of its architectural design and internationalisation of its teaching programmes (Lalu, 2012; Murray, 2012), and thus asserted its independence and aligned itself to democratic values of the rest of the free world. The text above appears to be a recontextualisation into the new South Africa of its (UWC's) past experiences and related discourses. At the same time the terminology is reframed as promotional discourse rather than as socio-political discourse. However, through blending current transformation discourses with its own struggle experiences, UWC remediates and recreates (Prior \& Hengst, 2010) in the present the fight it waged against the apartheid regime to 'advance and protect the independence of the academic enterprise' and to 'develop effective structures and conventions of governance, which are democratic, transparent and accountable'. The fight against the undemocratic apartheid government in which UWC took a leading role in championing academic freedom, accountability and transparency (cf. Lalu \& Murray, 2012), is transformed in the new South Africa into the university's new role to 'assist educationally disadvantaged students gain access to higher education and succeed in their studies'. This interface between the past and the present is designed to portray itself not only as a champion of societal freedom, but also as a beacon for academic freedom, thereby articulating a desirable identity for itself to potential students, South African community and the world.

UWC uses its embracing diversity at the height of apartheid as marketing point. Thaver and Mahlck (2008) describe the concept of diversity as referring to the ways in which institutions approach the management of those social groups, which are not part of the mainstream in society. Issues of ethnic/racial and gender diversity, which as noted elsewhere, form critical components of both MoE (1997a, 1997b) find focus in the mission statement as can be seen from the following extract:

Seek racial and gender inequality and contribute to helping the historically marginalised participate fully in the life of the nation ... cooperate fully with other stakeholders to develop an excellent, and therefore transformed, higher education system.

Thus, one can say that the UWC claims to play an important role in the emergence of the new democratic social order with racial and gender parity. 


\section{Recontextualising the 'white' past at UCT}

UCT's mission statement can be summarised as foregrounding its quality of teaching and research. While acknowledging the need for equity and redress of previously marginalised groups, it emphasises provision of lifelong skills knowledge and versatility to meet the challenges of local and international needs.

\section{UCT's mission statement}

Our mission is to be an outstanding teaching and research university, educating for life and addressing the challenges facing our society.

Educating for life means that our educational process must provide:

- a foundation of skills, knowledge, and versatility that will last a life time, despite a changing environment,

- Research-based teaching and learning,

- Critical enquiry in the form of the search for new knowledge and better understanding, and

- an active developmental role in our cultural, economic, political, scientific, and social environment.

Addressing the challenges facing our society means that we must come to terms with our past, be cognisant of the present and plan for the future. In this, it central to our mission that we:

- recognise our location in Africa and our historical context,

- claim our place in the international community of scholars,

- strive to transcend the legacy of apartheid in South Africa and to overcome all forms of gender and other oppressive discrimination,

- be flexible on access, active in redress, and rigorous on success,

- promote equal opportunity and the full development of human potential,

- strive for inter-disciplinary and inter-institutional collaboration and synergy, and

- value and promote the contribution that all our members make to realising our mission. To equip people with lifelong skills we must and will:

- promote the love of learning, the skill of solving, problems, and the spirit of critical

- enquiry and research, and

- take excellence as the benchmark for all we do.

We are committed to academic freedom, critical scholarship, rational and creative thought and free enquiry. It is part of our mission to ensure that these ideals live; this necessarily requires a dynamic process of finding the balance between freedom and responsibility, rights and obligations, autonomy and accountability, transparency and efficiency, and permanence and transience; and of doing this through consultation and debated.

The mission Statement was formulated by a Working Group of the University Transformation Forum and was affirmed and adopted at a University Assembly on April 24, 1996.

Whereas UWC directly appropriates the social transformation agenda, UCT, a previously white institution does the same indirectly. Second, UCT also claims struggle credentials covertly and it also pledges to address the challenges faced by the society. It reframes its identity by repositioning itself as part of the solution in the transformation agenda. 
For example, the statement starts:

Our mission is to be an outstanding teaching and research university... Educating for life and addressing the challenges facing our society...

Then it explains its interpretation of the phrase that reads: 'educating for life'. In this statement, the possessive adjective 'our' shows the collective, confident, and assertive university team which is also indirectly claiming struggle credentials by not mentioning its past experience in the liberation struggle, but by through altruism and identifying itself with those that suffered at the hands of the apartheid. Apart from constructing itself as being at the centre of social transformation, UCT constructs itself as a leader in the world of academia. The reference to quality outputs recreates and recounts the university's academic activity as modelled on industrial production. Moreover, the use of the adjective 'outstanding', is designed to project a prestigious stance as it describes the university as an exceptional institution. Even the phrase 'educating for life' compliments the quality of education they provide as permanent and it adds up to the unique and prestigious identity the university is captivating in advertising itself. This supports Wernick's (1991) argument that universities are now entangled in competitive, promotional culture.

The middle part of the mission statement further reconstructs UCT a previously white institution into a new inclusive identity. This is done through claiming a localised space in Africa. UCT thus divorces its 'white' and European-oriented past for an African identity:

it is central to our mission that we recognise our location in Africa...strive to transcend the legacy of apartheid in South Africa and to overcome all forms of gender and the other oppressive discrimination...

These remarks show UCT appropriating a mixture of social, political, and gender discourses as a way to claim social transformation as its own agenda. Specifically, this appears to be in part a reframing into promotional discourse of Section 1.14 of MoE (1997a) cited above. The phrase 'strive to transcend the legacy of apartheid in South Africa' juxtaposed as it is here with ' ... location in Africa ...' has by design or default double meaning. First, it can be seen as UCT owning up to its past as a white institution at which non-white groups were denied access. Second, the phrase puts UCT at the centre of the fight for emancipation and the struggle against the apartheid legacy. The latter was claimed by UWC in its mission statement. In this way like UWC, UCT has put itself at the centre of the government's transformation agenda. Additionally, UCT claims a shared common ground with (African) readers through constant use of the pronouns 'we' and 'our'. This in turn enables UCT to subtly claim a collective African identity, while divorcing itself from its British (white) heritage. In addition, in remediating Section 1.21 in MoE, 1997a, p. 12) entitled 'Quality' about the need for higher education to pursue 'the principle of quality [by] maintaining and applying academic and educational standards, both in the sense of specific expectations and requirements that should be complied with, and in the sense of ideals of excellence that should be aimed at' the clause 'we must take excellence as the benchmark for all we do' serves to position the university as a prestigious institution driven by quality and it also serves as a way of advertising itself to potential 
students or stakeholders. Wernick (1991, p. 181) points out that the generalisation of promotion, has a communicative function as discourse can be perceived as 'a vehicle for selling goods, services, organisations and ideas or people across orders of discourse'. UCT chooses inclusivity and superiority in academia as one of points of reference to make it admirable and to mark its idiosyncratic identity from other universities under study.

Arguably, the phrase 'be flexible on access in active redress and rigorous on success' is (almost) not only a direct quote from government's policy document cited elsewhere, it can also be taken to mean that UCT is aware of its past injustices and sees 'redress' as a way to atone the past wrongs. Thus, it can be said that this is a social discourse designed to provide a pleasant and egalitarian learning environment open to everyone in the new era. In these phrases too, the blending of educational and social discourses is seen as another way UCT subtly claims 'struggle credentials' through drawing on and reframing past and current social discourses on 'restructuring'. This enables UCT to claim ownership of social transformation as crystallised in the phrasing in; '[we] promote equal opportunity and the full development of human potential'. Whereas the first part seems to emphasise the egalitarian dispensation in late modern society, the latter is a general social statement which could be taken to refer to the black empowerment equity - the South African government's blueprint to fast track blacks into the formal economy and leadership positions denied to them during the apartheid era.

Therefore, through this recreated identity the university is able to redirect readers' attention away from its past to the new mission in which it strategically claims to be in the forefront, promoting education freedom and diversity in the country and globally. UCT subtly selects the paradigmatic choices in presenting an acceptable inclusive identity in the new South Africa. The discursive representations show that the university is cast in a serving, meeting, and responding role to the needs of the society and actively reshaping them. Rather than write in such a way that draws a sharp contrast between the past and the present identities, UCT mission statement is written in such way that current aspirations blur its past role. UWC does the opposite as it openly flaunts its past, especially the struggle credentials as an inclusive university to reshape its current identity.

It is noteworthy that UCT casts the relationship between the university and the economy world as a partnership. This foregrounds equality and its pledge to eradicate the social ills that were imposed by the previous ruthless regime. This move foregrounds social responsibility while the commercial aspect is downgraded into the background. However, the reference to excellent quality output projects UCT academic activity to be modelled on industrial production comparable to the best universities in the world. Additionally, UCT emphasises not only social and economic transformation, but also uses the language of rapid movement, such as 'rigorous, active'. This ties in with Barnett's (2003, p. 66) characterisation of the entrepreneurial university as being 'restless' and 'always on the move'. Thus, UCT is able to draw from the different discourses available to put across a forward-looking mission statement that is ideal for cultivating the society that was once tormented by the ruthless hand of the apartheid regime.

\section{Rehabilitating Afrikaans}

SU's mission statement is similar to UCT's in as much as it emphasises excellence in academic and research activities, and it places the community at the centre of its endeavours. Like UCT, SU 
stresses that it seeks to contribute and be a major player in South Africa's, Africa's and global aspirations.

\section{SU's mission statement and vision}

The raison d'être of the university of Stellenbosch is to create and sustain in commitment to the academic ideal of excellent scholarly and scientific practice an environment within which knowledge can be discovered, can be shared and can be applied to the benefit of the community.

With this vision statement, SU commits itself to an outward-oriented role with South Africa, Africa and globally. SU:

- is an academic institution of excellence and a respected partner

- contributes towards building the scientific, technological, and intellectual capacity of Africa

- is an active role-player in the development of the South African society

- promotes Afrikaans as a language of teaching and science in a multilingual context

- promotes equity, in terms (inter alia) of the bringing about of a corps of excellent students and academic and administrative staff members that is demographically more representative of South African society, must be fundamental to all our actions, including our redress of the inequalities of the past and our repositioning of the University for the future. (Extracts from the Strategic Framework)

What stands out in SU's mission statement is its overt choice to maintain its previous identity centred on Afrikaans through casting it in a new and positive way. It redefines Afrikaans and weaves it into the multilingual discourses that have become part of the new South Africa's transformation agenda.

SU opted for a mission statement that is overtly painted with the prestige discourse to persuade potential stakeholders as compared to the other universities. The mission statement reads in part as:

The raison d'être of the University of Stellenbosch is ... to create and sustain, in commitment to the academic ideal of excellent scholarly and scientific practice, an environment within which knowledge can be discovered, can be shared, and can be applied to the benefit of the community.

The presence of a French phrase in the English text, which means, 'motive', is not by accident or lack of English phrases. It appears calculated to cast the university as a prestigious and sophisticated 'global' institution. Ironically, even though the phrase is often used in English discourses, it gives credence to SU's stance to promote multilingualism and diversity in the modern and globalised world.

Downplaying the perception in the past of Afrikaans as the language of oppression, the university does not hesitate to publicly announce that it is an Afrikaans medium institution which 'promotes Afrikaans as language of teaching and science in a multilingual context'. The SU mission statement reconstructs Afrikaans as marginalised as the other indigenous languages 
such as Xhosa. Thus, in solidarity with other marginalised languages, SU makes its mission to help develop Afrikaans as a language of education. In the process, SU not only acknowledges multilingualism as inscribed in the South African constitution, it also appropriates government agenda to promote multilingualism and diversity as its own mission. Therefore, the images of an institution, which was in the past seen as part of the apartheid machinery and Afrikaans as the language of oppression, in the mission statement, are semiotically re-materialised to carry new and desirable characteristics to all racial groups.

Moreover, the choice of words used such as 'to create, sustain, academic, ideal, of scholarly, and scientific practice' is intended to give the reader the picture that the university is not only innovative but is also a global player with an international status. These are the kinds of common vocabulary used in the world organisations such as United Nations, World Bank, and other international corporations, and are also examples of globalisation discourse (Fairclough, 1993, 2003).

Like the other universities, $\mathrm{SU}$ also emphasises inclusiveness and tries to put itself at the centre of the transformation agenda, albeit covertly by articulating its aspired role in the present era and asserting its African identity. SU is reconstructed not only as an 'Active role-player in the development of the South African society ...' but also on the African continent. This is shown by the absolute manner in which it identifies itself as an 'academic institution of excellence and a respected partner [which] contributes towards building the scientific, technological, and intellectual capacity of Africa'. Even from these restricted textual environments, one can still identify key motifs and discursive representations that the university holds: the university puts itself at the forefront of Africa's technological and intellectual development as part of its identification process. Thus, even though there is no mention of struggle credentials, the university subtly manages to push the transformation agenda. This is because its claim to be the driving force behind the African continent's progression into the economy world outs it at the forefront of Africa's political and socio-economic emancipation. In similarity to UCT, this move backgrounds the commercial exchange processes involved and foregrounds helping Africa (the third world) to prosper. This helps SU not only to divest itself from the negative associations of the past, but it effectively renegotiates its relationship with local, national, regional, and the global institutions and role players. In essence, SU repositions itself to aspire to the same dictates as UWC and UCT.

\section{Summary and conclusion}

By using interdiscursivity and intertextuality together with the notion of remediation, we are able to show that the universities are not merely referring to prior texts; they use these texts as semiotic resources, which they transform into mission statements used to market themselves and to construct differentiated brand identities. Although drawing on the same semiotic materials, choices in selection, restructuring and manner of transformation enable the universities to achieve expanded meanings, which markets them as unique and differentiated brands.

From the points raised above, we argue that in the democratic dispensation in South Africa, the commodification of struggle and transformation discourse has blurred the trajectories of the historicity of the universities in such a way that they appear not dissimilar and show a rejection of the apartheid values and ideologies under which the institutions were created. The 
boundaries between previously white and previously black universities has been further blurred by the changing student and academic profiles as the transformation discourses on which the universities draw their inspirations demand that there must be no gender, racial, ethnicity, regional (etc) biases in the make-up of the universities' populace. Moreover, this call for openness and inclusive citizenship has been blended with globalising aspirations in which universities worldwide strive for equal opportunities and global transnational recognition. What we saw in the previous sections is that the appropriated discourses have been repurposed for marketing the universities as objects of desire to which all racial, ethnic, national, etc. groups are welcome to consume the best in academia. This has led to commodification of struggle and transformation discourses, leading also to new forms of contested values, identities and in particular, notion of community. The apartheid ideology of a community as being constituted by people who share a particular race or ethnicity has been replaced by the notion of nonbounded and non-homogenous people who share similar vision of freedom and common good of humanity. Thus, even though UWC as a previously black university and UCT and SU as previously white universities followed different paths and had difference experiences, the new dispensation has directed them towards a similar goal of an equitable and transformative society in which race and ethnicity are not a differentiating and disqualification factor.

Therefore, the repurposing of struggle and current social transformation discourses into marketisation discourses in mission statements projects the three universities as forwardlooking. The discourses are designed to be consumed as inspirational but differentiated brand identity positions, which in turn provide direction, purpose, and meaning to each of the three universities (Aaker, 1996). In short the appropriated discourses shape the three universities' identities and how they are to be perceived and consumed.

The study shows that the ideology of a non-racial society and equal opportunities championed in post-apartheid South Africa as well as translocal and transnational demands for academic excellence have necessitated the need for South African universities to develop and cultivate new entrepreneurial endeavours that are locally located and relevant but international in scope. Race as a defining feature of the universities has been replaced with commoditised discourses of transformation, redress, and equal opportunity. The study demonstrates that each of the universities have reworked cultural, political, educational, and promotional materials to create commoditised discourses of transformation and marketisation. In the process they have created independent and unique identities which they use as points of sale in the 'worldwide market for students and the ceaseless search for research funding and prestige' (Deem, Lucas, \& Mok, 2008, p. 84).

\section{Disclosure statement}

No potential conflict of interest was reported by the authors.

\section{Notes on Contributors}

Felix Banda lectures in the Department of Linguistics at the UWC, where he teaches undergraduate and postgraduate courses in multilingualism in society and education and technology-mediated business communication and intercultural communication. His research interests include the discursive construction of identities in society and education and the semiotics of corporate identity branding and advertising, youth, and hip hop cultures. 
Linguistics Department, University of the Western Cape, P/B X 17, Bellville 7535, (Cape Town), South Africa. E-mail: fbanda@uwc.ac.za

Lynn Mafofo is a Ph.D. candidate in the Department of Linguistics at the UWC. Her research interests are in the sociolinguistics of media, business and organisational communication, institutional branding, corporate identities, and globalisation in late modern society. Linguistics Department, University of the Western Cape, P/B X 17, Bellville 7535,

(Cape Town), South Africa. E-mail: lymafofo@gmail.com

\section{References}

Aaker, D. (1996). Building strong brands. New York, NY: Free Press.

Alexander, N. (1999). African Renaissance without African languages. Social Dynamics, 25(1), 112.

Altbach, P. G., \& Knight, J. (2007). The internationalisation of higher education: Motivations and realities. Journal of Studies in International Education, 11(3/4), 290-305.

Atkinson, D. (1997). A critical approach to critical thinking in TESOL. TESOL Quarterly, 31(1), 7194.

Bangeni, B., \& Kapp, R. (2005). Identities in transition: Shifting conceptions of home by black South African university students. African Studies Review, 48(3), 1-19.

Barnett, R. (2003). Beyond all reason living with ideology in the university. Buckingham: SRHE and Open University Press.

Bee, S. B. (2001, December). A critical discourse analysis of the mission statement of education in Singapore. A paper presentation for AARE, 2001 conference, Nanyang Technological University, School of Electrical and Electronic Engineering, Singapore.

Benwell, B., \& Stokoe, E. (2006). Discourse and identity. Edinburgh: Edinburgh University Press. Bhatia, V. K. (2004). Worlds of written discourse: A genre-based view. London: Continuum. Blommaert, J. (2010). The sociolinguistics of globalization. Cambridge: CUP.

Boesak, A. (2006). African Renaissance and spirituality. International Journal of African Renaissance, $1(1), 175-183$.

Buhle, Z. (2013, June). Talk white and we'll be friends. IOL Lifestyle. Retrieved April 10, 2015, from http:// www.iol.co.za/lifestyle/family/friends/talk-white-and-we-ll-be-friends1.1529977\#.VcIO-ngTH8s

Bulotaite, N. (2003). University heritage - an institutional tool for branding and marketing. Higher Education in Europe, 28(4), 449-454.

Cooper, D., \& Subotsky, G. (2001). The skewed revolution, trends in South African higher education: 1988-1998. Cape Town: University of the Western Cape.

Deem, R., Lucas, L., \& Mok, K. H. (2008). Transforming higher education in whose image? Exploring the concept of the 'world-class' university in Europe and Asia. Higher Education Policy, 21, 83-97. DeGenaro, W. (2009). Legitimating corporate education: Two-year college mission statements. The International Journal of Critical Pedagogy, 2(1), 100-118.

Fairclough, N. (1993). Critical discourse analysis and the marketisation of public discourse: The universities. Discourse and Society, 4(2), 133-168.

Fairclough, N. (2005). Analysing discourse - textual research for social research. New York, NY: Routledge.

Friedman, T. (2005). The world is flat: A brief history of the twenty-first century. New York, NY: Farrar, Straus and Giroux.

Gee, J. P. (1990). Social linguistics and literacies: Ideologies in discourse. London: Falmer. 
Gerhart, G. M. (1978). Black power in South Africa: The evolution of ideology. Berkeley: University of California Press.

Gilje, O. (2010). Multimodal redesign in filmmaking practices: An inquiry of young filmmakers' deployment of semiotic tools in their filmmaking practice. Written Communication, 27(4), 494-522.

Hibbert, L., \& Van der Walt, C. (2014). Biliteracy and translanguaging pedagogy in South Africa: An overview. In L. Hibbert \& C. Van der Walt (Eds.), Multilingual teaching and learning in higher education in South Africa (pp. 3-14). Clevedon: Multilingual Matters.

Iedema, R. (2003). Multimodality, resemiotisation: Extending the analysis of discourse as multisemiotic practice. Visual Communication, 2(1), 29-57.

Johnstone, B. (2008). Discourse analysis (2nd ed.). Oxford: Blackwell.

Kapp, R., \& Bangeni, B. (2011). A longitudinal study of students' negotiation of language, literacy and identity. Southern African Linguistics and Applied Language Studies, 29(2), 197-208. doi:10.2989/ 16073614.2011.633366.

Lalu, R. (2012). Constituting community at the intellectual home of the left. In R. Lalu \& N. Murray (Eds.), Becoming UWC: Reflections, pathways and unmaking Apartheid's legacy (pp. 105-115). Bellville: UWC CHR.

Lalu, R., \& Murray, N. (2012). Introduction. In R. Lalu \& N. Murray (Eds.), Becoming UWC: Reflections, pathways and unmaking apartheid's legacy (pp. 12-21). Bellville: UWC CHR.

Madiba, M. (2014). Promoting concept literacy through multilingual glossaries: A translanguaging approach. In L. Hibbert \& C. Van der Walt (Eds.), Multilingual teaching and learning in higher education in South Africa (pp. 68-87). Clevedon: Multilingual Matters.

Mafofo, L., \& Banda, F. (2014). Accentuating institutional brands: A multimodal analysis of the homepages of selected South African universities. Southern African Linguistics and Applied Language Studies, 32(4), 417-432. doi:10.2989/16073614.2014.997068.

Makalela, L. (2014). Teaching indigenous African languages to speakers of other African languages: The effects of translanguaging for multilingual development. In L. Hibbert \& C. Van der Walt (Eds.), Multilingual teaching and learning in higher education in South Africa (pp. 88-106). Clevedon: Multilingual Matters.

Makgoba, M. W. (1999). African Renaissance: The new struggle. Johannesburg: Mafube.

Mautner, G. (2005). The entrepreneurial university: A discursive profile of a higher education buzzword. Critical Discourse Studies, 2(2), 95-120.

Mbeki, T. (1998, April). The African Renaissance, South Africa and the world. Speech by Deputy President Thabo Mbeki at the United Nations University, Tokyo, Japan.

Ministry of Higher Education. (1997a). The White Paper 3 on transformation of higher education. Pretoria: Government Printers.

Ministry of Higher Education. (1997b). The Higher Education Act 101 of 1997. Pretoria: Government Printers.

Moodie, G. (1994). The state and the liberal universities in South Africa: 1948-1990. Higher Education, 27, 1-40.

Morgan, G. (1983). Beyond method: Strategies for social research. Beverly Hills, CA: Sage.

Murray, N. (2012). A campus apart. In R. Lalu \& N. Murray (Eds.), Becoming UWC: Reflections, pathways and unmaking apartheid's legacy (pp. 58-83). Bellville: UWC CHR.

Osman, H. (2006). An investigation of socio-cognitive strategies in university. ESP Malaysia, 12, 39-51. Retrieved $\quad$ February $19, \quad$ 2009, from http://www.penerbit.utm.my/OnlineEspMalaysia/12/Artikel_39_51.pdf 
Prior, P. A., \& Hengst, J. A. (2010). Introduction: Exploring semiotic remediation. In P. A. Prior \& J. A. Hengst (Eds.), Exploring semiotic remediation as discourse practice (pp. 1-23). New York, NY: Palgrave Macmillan.

Scollon, R., \& Scollon, S. W. (2003). Discourses in place: Language in material world. New York, NY: Routledge.

Teo, P. (2007). The marketisation of higher education: A comparative case-study of two universities in Singapore. Critical Approaches to Discourse Analysis Across Disciplines, 1(1), 95-111.

Thaver, B., \& Mahlck, P. (2008). Globalisation, diversity, and academic practice: Reflections from South Africa and Sweden. Stockholm: Stockholm University Press.

Van Riel, C. B. (1997). Research in corporate communication: An overview of an emerging field. Management Communication Quarterly, 11(2), 288-309.

Wernick, A. (1991). Promotional culture. London: Sage.

Wolpe, H. (1995). The debate on university transformation in South Africa: The case of the University of the Western Cape. Comparative Education, 31(2), 275-292. 